\title{
The possibilities of meaning creation in pedagogic communication
}

\author{
Enikő Szőke-Milinte
}

\begin{abstract}
The main characteristic of pedagogical situations is that targeted, planned and organized developmental activities are ongoing, in order to accomplish the personality of the educated person. Pedagogical situations are developing activities, characterized by their direct or indirect educational effect due to their subject-specific and problem-specific, communication-embedded nature or communication. Pedagogical situations are developing activities that are characterized by the fact that they communicate directly or indirectly by subject-specific and problem-specific communication. Therefore, the communicative context in which the personality development activity takes place cannot be indifferent to pedagogy. Each developing activity has a communicational context, and in fact, communication is the main effect of personality development. Therefore, the examination of pedagogical communication is a fundamental task of pedagogy: the awareness, development and application of pedagogical communication frameworks and possibilities are the minimum conditions of pedagogical effect and personality development. This study applies a specific communication theory to interpret the context of pedagogical communication.
\end{abstract}

Keywords: meaning creation; storytelling in communication; pedagogical and communication rules and laws

Subject-Affiliation in New CEEOL: Social Sciences - Education - School Education

DOI: $10.36007 /$ eruedu.2021.2.48-57

\section{Introduction}

Communication competence, as inherent in its nature, is organised by three toolkits: the system of skills and abilities, communication knowledge and attitudes supporting communication behaviour (Szöke-Milinte, 2012). The past decade's thinking about communication development was determined by the study and description of the development of skills and abilities. It also entails that the development of skills and abilities was nearly exclusively held responsible for the development of communication competence by the researchers of the field. The dominance of skill and ability development activities was most conspicuous in a wide range of scenes of education. 
The dominance of skill and ability development is not problematic as, along with the communication skills, the participants' emotions and attitudes also develop through the carefully selected activities. Furthermore, on condition that the activity is properly discussed, and sufficient time is devoted to reflections, making participants aware of the process of development provides room for the discussion of a certain kind of knowledge, or even perhaps of some theoretical issue concerning communication.

Generally, however, the trainings and activities meant to develop communication competence do not meet the above described and desired level of awareness. In practice, the only memory the participants usually have of the development is that they had a good time while engaged in a funny activity. While this is a most joyful experience, the development of communication skills thus fails to meet the professional requirements.

Successful communication rests on a highly developed level of communication competence and a coordinated and harmonious operation of its component toolkits. Consequently, the failure of communication can either be put down to its component toolkits being underdeveloped or not operating properly. Much as the operation of the communication skills on an elevated level is truly an important measure of communication success, in itself it is not guaranteed. It is also necessary to possess and use informational cognitive components, i.e. knowledge, rules, governing patterns, theories, which buttress the comprehension of communication behaviour.

This paper focuses on the component toolkit of informational knowledge, a fundamental communication theory. Knowledge, awareness and implementation of this theory helps recognize and thus avoid miscommunication. The applicability of this theory is demonstrated through pedagogical communication situations by this paper.

\section{A possible framework for pedagogical communication, that is, the cognitive component of communication competence}

Let us accept László Zrinszki's interpretation (Zrinszky, 1996) of the concept of pedagogical communication, that is, pedagogical communication occurs in a communication form governed by pedagogical objectives, regulated in compliance with pedagogical considerations usually within an institutional framework, and takes place in the direct personal contact of pedagogues and students often through the use of certain mediation. It is not only the quality of the contact between the communicators, but also the personality development and academic performance of the students that depends on the success of pedagogical communication.

The theory of the 'Coordinated Management of Meaning' (CMM), developed by a pair of authors, Pearce and Cronen, is a theory of interpretation that offers pedagogical communication useful basic principles and rules for consideration (Griffin, 2003). It is a paradigm that helps understand and avoid problems occur- 
ring in course of pedagogical communication, or, in case it proves impossible, it contributes to their effective solution.

The theory rests on three important social-constructionist basic principles. One of them claims that we create the events and objects of our social worlds through communication, which implies that these are not a priori given as it was presumed by empirical researchers. Adapting this claim to the realm of the school, it means that the scenario of the classroom and school events is not preliminarily determined, but rather created by the participating students and teachers. Consequently, several good scenarios may exist simultaneously, in other words, the dynamics, the scenario of good communication is plural by nature. That is the very reason why no absolute truths are possible to assert regarding, for instance, what the scenario of good classroom cooperation is like, instead, we can only assume the existence of a variety of good communication scenarios created in accordance with the expectations and ideas of the participants of school communication.

This theoretical basic claim can only prevail optimally in pedagogical communication if we consider the process of communication democratic in which each participant is able to represent and demonstrate his/her own assigned meaning, which implies participation in the communication as one who asserts his/her ideas about desirable communication. In pedagogical communication, because of the differences in the participants' backgrounds, i.e. the inherent differences of children and adults in terms of preparedness, and the specificity of the situation, i.e. its hierarchical nature, the participants are enabled to create communication events and represent their assigned meanings in different ways. Thus, in pedagogical situations, in case the pedagogue in possession of an extra knowledge takes on the responsibility of creating communication events, it is crucial that he/she does it only to an extent which does not condemn the rest of the participants, that is, the students, to passivity.

Pedagogical laws pursuant to the basic claim that 'we create the events and objects of our social worlds through communication':

In the pedagogical situation the 'world' created is one which we create in and we do it by communication.

It depends on the participants, teachers and students, what kind of communication events are created: ones in which they feel comfortable and respected, in which they are willing to participate, or just the opposite, ones that they would readily escape from.

Each participant bears individual responsibility for the events created by them; each participant is to take responsibility for the situation created.

The communication event is determined not only by the circumstances, but also by the interpretation the participants attach to them, so interpretation models are to be outlined, which can be used to understand harmoniously the changing - and sometimes far from ideal - circumstances. E.g. how do the students and the teacher view unsuccessful test results: either as an irreversible failure, or as the starting point for planning further development.

The participants must acquire the possible interpretation schemes that can be used to create communication events according to their needs. Still refer- 
ring to the example of unsuccessful test results, if they are interpreted as a means of diagnostics which helps surface the defects of teacher and students alike, the participants will have an opportunity to create further communication events, e.g. correction, practice, a new test in a way that they could meet the needs of all involved.

The communication events created based on the commonly outlined interpretation schemes will be acceptable for all involved. Still referring to the example of unsuccessful test results, it can be afternoon practice, peer support, forming learning groups, etc.

Several good scenarios are possible as a good scenario is one that satisfies the needs of all participants. In pedagogical communication as many good scenarios should be created and tried as possible.

Another core claim of the theory is that 'we cannot seek certainty', there are no 'omnipotent' rules for how one has to or can behave. What is necessary instead is that the participants learn to remain curious and to adapt their behaviour to the ever-changing circumstances (Griffin, 2003, 65-92). It is a profound recognition for pedagogical communication that the trainee teacher or the practising pedagogue cannot and should not teach the scheme of effective communication, since the meaning of effectiveness varies according to different situations. What a trainee teacher must be prepared for is for him/her to be able to teach the students how to enrich continuously and adaptively apply their existing communication component set in communication situations.

Pedagogical laws pursuant to the 'we cannot seek certainty' core principle:

The communication participants are supposed to be free of preconceptions about the communication and the communication partners, and are supposed to be curious of the diverse range of worlds possible to create through communication.

The communication scheme, i.e. the scenario is to be built up by the collaborating participants, which in this way is acceptable for all, and which makes their meaning assignment successful.

The communicators - teachers, students - participating in the communication are to retain their openness to and curiosity of the secret inherent in communication, and are to participate in the communication with the expectation to learn something about themselves, the other, or the world which they do not know yet.

The participants of the communication - teachers, students - are to enrich continuously their communication component toolkit, and are to apply it adaptively in most varied communication situations.

The third core principle the theory is built upon is that it is only through active participation in the communication process and never through an outside observation that the proper course of action, the proper steps can be seen (Griffin, 2003, 65-92). Correct communication behaviour can be learnt neither from a book, nor from a teacher's description; the observation of communication is essential, however, what is much more important is individual participation and gaining personal experience. 
Pedagogical laws pursuant to the 'individual participation and gaining personal experience' core principle:

It is indispensable to the success of pedagogical communication that as many kinds of communication situations should be created and experienced by the student as possible.

The varied nature of pedagogical communication situations makes it possible for the participants to gain experience related to the various scenarios and to try them in practice.

The personal engagement in meaning assignment makes it possible for the participants to enter into a dialogue with themselves, the communication partner and the object of communication, i.e. the given problem.

Personal engagement in pedagogical communication entails engagement in the creation of a scenario that optimally satisfies the needs of each participant, i.e. one where the legitimacy of each need is never questioned, where the face of each participant is protected, and where the participants accept one another.

The pedagogue is to support the personal engagement of the students in meaning assignment.

The authors borrowed the three core principles above from social-constructionist theories, but the three below are laid down on their own to demonstrate the theory.

According to the fourth core claim, the experience gained by the persons-in-conversation during the speech act corresponds with the fundamental social process of human existence. In the fundamental social process, in course of the conversation, the connection and personalities of the persons-in-conversation are created (Griffin, 2003, 65-92). This process has a particular importance in pedagogical communication as the child's personality is permanently developing, so the pedagogical influences that prevail in communication encounter the sensitivity of the child's developing personality.

Pedagogical laws pursuant to the in course of the conversation, the connection and personalities of the persons-in-conversation are created' core principle:

The love, respect and acceptance felt towards the child can be conveyed by respectful, kind and accepting communication.

If the pedagogue, thorough pedagogical communication, conveys that the child is valuable, worthy of love and acceptable, the child will become valuable, worthy of love and acceptable (Pygmalion-effect).

The utterances of the pedagogue are to be individually tailored so that they could really contribute to the development of each child's personality.

Respectful, kind and accepting communication forms the basis of the good relationship between the child and the pedagogue.

According to the fifth core claim of the Coordinated Management of Meaning theory 'the way people communicate is often more important than the content of what they say', in other words, in communication it is the form that determines the events of social spaces (Griffin, 2003, 65-92). The dry, informal, objective 
form could be suitable for sharing information, however, when it comes to pedagogical communication, what matters is not only sharing information, but personality development as well. That is why utterances like the following make sense: 'As I see a smart child is raising his hand and will tell us the solution.'

Pedagogical laws pursuant to 'the way people communicate is often more important than the content of what they say' principle:

Despite the fact that the teacher has a rather limited time in the lesson as a result of having to focus on the academic content to convey, the form of communication is of key importance.

Through his/her communication utterances the pedagogue must also take care of and foster his/her connection with the students.

The sixth core claim based on which the theory is outlined is that the actions of the persons-in-conversation are reflexively reproduced as the interaction continues', so any action we take have consequences and will bounce back and affect us (Griffin, 2003, 65-92). It is similar to the mirror effect associated with non-verbal communication, but it also goes beyond. The latter two claims correspond to Martin Buber's idea of mutuality inherent in relationships (Buber, 1999). Buber points out that as our own personality is created in a relationship under the influence of the partner, the partner's personality is also created and develops in the same relationship under our influence. Thus, the relationship involves a double responsibility: I am responsible for my partner and for myself. As we change in a relationship, our partner changes simultaneously: if we want our partner to change, for instance to be kinder to us, we must also change, and must assume more kindness in our relationship.

Pedagogical laws pursuant to 'the actions of the persons-in-conversation are reflexively reproduced as the interaction continues' principle:

The pedagogue must change towards the image he/she wishes the students to change towards.

The personal change of the pedagogue will initiate the change in the students' personalities.

The communication influences as pedagogical influences affect the pedagogue's and the students' personalities simultaneously.

The communication influences are essential components of both education and self-education.

Based on the above basic claims Pearce and Cronen hold that 'communication can be considered good if the participants can coordinate their actions in a way that their conversation lead to the construction of such social realities in which they can live comfortably, that is, in dignity, respect, happiness and love' (Pearce, 1994, 366). In these social realities the participants of a conversation are all present, behave adaptively and accept that several kinds of good behaviour exist, hence they contribute to shaping a more liveable, more humane world. 


\section{Storytelling}

Theorists hold that telling stories is the best means of creating and maintaining our social realities. The Coordinated Management of Meaning model identifies seven types of stories (LUUUUTT Model from CMM Institute for Personal and Social Evolution, adapted form of 2014). (Pearce \& Cronen, 2014)

Let us examine storytelling through a concrete example (see Figure 1). In the school canteen a Boy and a Girl are standing together in the queue (which they are not allowed to leave, and where overtaking is not allowed either). The Girl is making noise with a toy and enjoys the noise she is making. The Boy asks her to stop because the noise disturbs him. The Girl keeps making that noise, so the Boy shouts at her to stop. Then the Boy hits the Girl who starts to cry. The teacher punishes the Boy, he is not allowed to go to play to the school yard after lunch. The Boy starts to cry.

1 Stories lived: the communication pattern of which has been created together with those who were also involved; it is about how people try to coordinate their lives with those of others. (Boy: This noise is getting on my nerves, it feels as if a train was pounding in my head; she wouldn't stop, I feel frustrated, I'm shouting, I'm not allowed to leave the queue, I don't get lunch, I have no idea what to do; I kick her to make her stop, I feel guilty, I'm afraid of the consequences, I cry, I feel ashamed).

2 Stories told: narrative explanations; the persons-in-conversation try to establish meaning and coherence in their lives. (Boy: She was getting on my nerves, I asked her to stop, but she just would not stop, so I kicked her, then I felt ashamed in front of the teacher and my mother, I cried.)

3 Meta-stories: the manner of communication, the way stories are told expresses the relationship (manifested in mood for instance) of the persons-in-conversation with themselves, and with the object of the conversation (exaggerating, convivial, funny, honest, etc.). (Boy: I feel frustrated and nervous, I am angry with the Girl.)

4 Untold stories: the narratives that we do not wish to share with others because, for instance, we do not want to hurt the other or ruin his/her self-esteem, or perhaps jeopardize the relationship, or become vulnerable. (Boy: I have an over-sensitive ear, 'a bat ear', I perceive all sounds louder than the others, noises cause me great discomfort, especially if they are monotonously repetitive.)

5 Unknown stories: narratives which are unknown to us relating to a person or communication content. (Boy: I didn't know that if I had told the teacher about it, she would have allowed me to go forward or leave the queue.)

6 Untellable stories: narratives which are unknown or too painful, and thus impossible to tell. (Boy: I hate girls anyway, because they keep making fun of me because I don't understand what they are saying and what they are talking about.)

7 Unheard stories: narratives which the communication partners are not sensitive to, which they cannot hear'. (Boy: The Girl did not understand that monotonous noise disturbs me a lot.) 


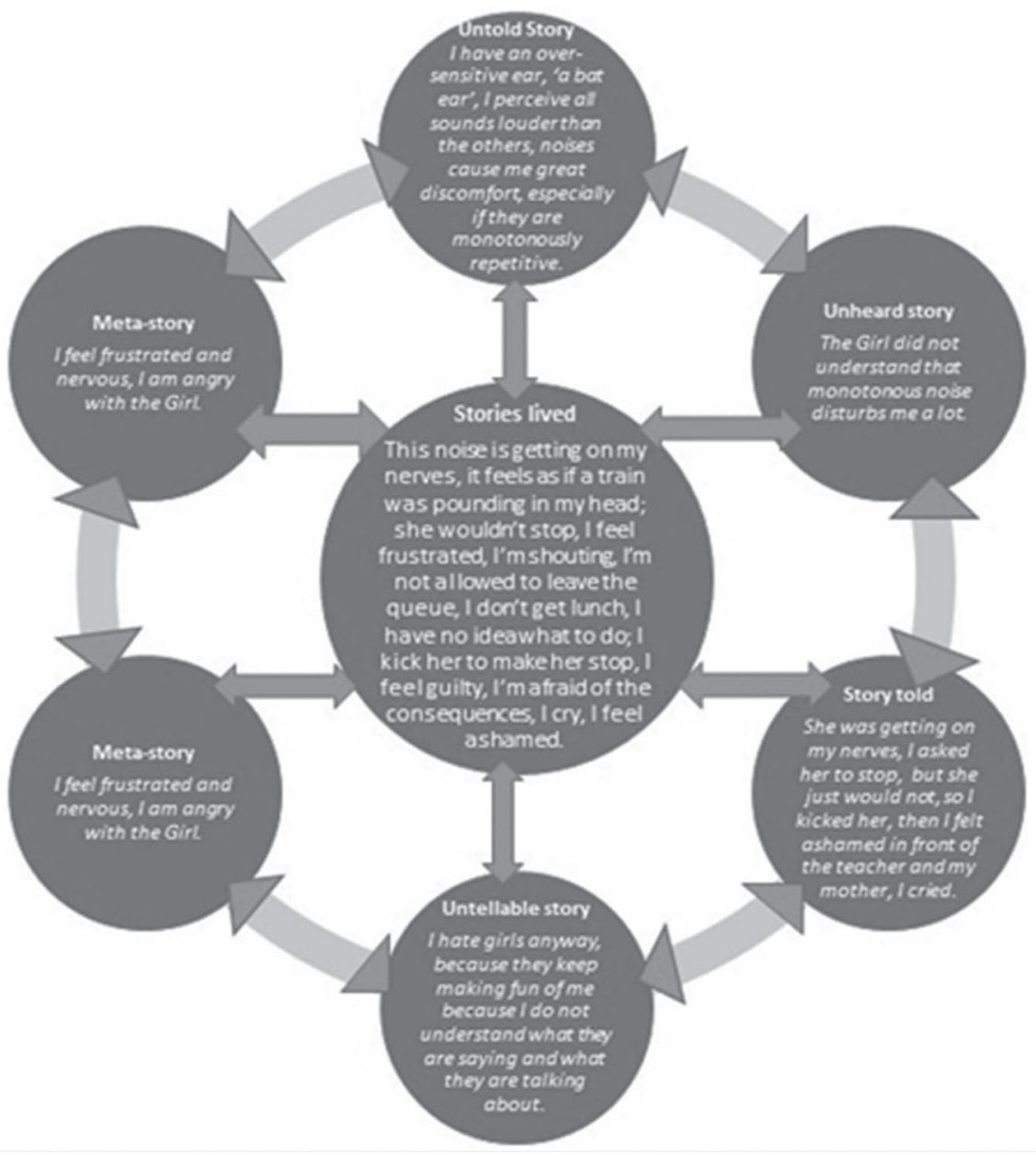

Figure 1: Telling stories

Pearce and Cronen hold that the stories differ in a certain communication situation, and even considerable tension may occur among them.

Stories told are coherent since we attach meaning to the story while telling it. Stories lived, however, are continuously being fragmented by our own and others' communication actions. The more we manage to make the stories told precise and make them uncover the unknown, untold, and unheard stories, the better we can match the stories told and the stories lived to each other, and this way improve.

In course of coordination 'people collaborating in an attempt to bring into being their vision of what is necessary, noble, and good, and to preclude the enactment of what they fear, hate, or despise' (Pearce \& Cronen, 2014).

When telling stories lived, it is essential to create and implement good communication patterns, schemes, scenarios, as this is through which the social reality, where we must spend a long time together, is created for ourselves and our partners. 
In pedagogical communication situations we get what we have created.

To create liveable 'worlds', personal involvement and a high degree of awareness is necessary in pedagogical communication. Communication is by no way automatic, as it is known that a carefully selected and formed utterance may lead to a wonderful effect on the communication partner, e.g. anger may disappear, or turn into rage. All we must do is to apply 'the rule of agreement': respect what the partner has created, and be open to what he/she is to construe.

This is something that a child at a very young age is by instinct capable of. If he/ she is told in the gym to 'run because a shark is coming and is going to catch us', he/she does not question this statement or receive it with scepticism, but immediately starts the 'escape run'. If, afterwards we tell him/her to 'hold on to the mast because the shark cannot catch us there', the child also follows the instruction without thinking, climbs up the wall bars and throws the rope to those who have not yet managed to climb up.

In classroom communication this rule can be rephrased as follows, 'start with a yes, and watch in what direction the communication unfolds'.

According to Pearce, W. Barnett and Pearce, Kimberly W. Barnett Pearce and Kimberly A. Pearce, dialogue is the proper form of communication to coordinate meanings in problematic situations. They regard the rule formulated in David Bohm's Theory of Dialogue and the dialogue ethics of Martin Buber as one to follow generally: suspend our own perspectives, our framework for interpretation, and maintain an unlimited openness to others (Pearce \& Cronen, 2014).

The non-exhaustive presentation of the core principles above enables the practising pedagogues and the students to answer the following questions with reference to their own communication (Bohm, 2011).

What should they do in a certain communication situation?

What style and what utterances should they use in a certain communication situation (respectful, kind, objective, inspiring, etc.)?

What relationship is worth building in the communication situation (cooperating, competitive, conflicting, etc.)?

What identity, self-image should they assume (the caring person, the person taking on responsibility, the accepting, or the tolerant person, etc.)?

What culture should they represent and build (democracy, autocracy)?

Practising pedagogues, teacher trainees and students will all view the operation of communication with an elevated level of awareness; they will formulate valid answers to questions targeting the operation of communication:

What communication situations should they create for the communication partners?

What surplus information is inherent (and what can be predicted based on this) in the language use of the communication partners?

What forms of speech and utterances will be evoked by their own communication?

Who will get involved in and who will abstain from communication? 
Who is and who is not addressed to by the applied communication?

In pedagogical communication the pedagogue operates as a facilitator, which means that he/she represents and applies all the principles and rules we have become familiar with through the above presentation of the theory. Furthermore, he/she helps form and coordinate the schemes, rules, patterns, and points of view appearing in the stories lived included in the communication. The pedagogues' approach to the coordination of a variety of communication forms hence becomes the coordination of paths which lead to and which help us live up to our humanity. The above theoretical framework can only be experienced through practice in a longer, attitude-shaping process. The preconditions of its applicability are: full attention, being an adult in terms of communication, and awareness.

\section{References}

Bohm, D. (2011): A dialógusról. SoL Intézet, Budapest.

Griffin, Em (2003): Bevezetés a kommunikációelméletbe. Harmat Kiadó, Budapest, 6592.

http://rosalia.mercubuana-yogya.ac.id/wp-content/uploads/2016/04/ebooksclub.org_A_First_Look_at_Communication_Theory__8th_Edition_.pdf (2019.02.21.)

Pearce, W. Barnett \& Cronen Vernon: Coordinated Management of Meaning (CCM). In. Griffin Em - Ledbetter Andrew - Sparks Glenn (2014): A First Look of Communication Theory. 8 th Edition. 66-80.

Pearce, W. Barnett (1989): Interpersonal Communication: Making Social Worlds. HarperCollins. New York.

Szőke-Milinte, Enikő (2012): A kommunikációs kompetencia a 2012-es NAT vitaanyagában. In: Anyanyelv-pedagógia 2. http://www.anyanyelv-pedagogia.hu/cikkek. php?id=380 (2019.02.21.)

Zrinszky, László (1996): Bevezetés a pedagógiai kommunikáció elméletébe. Nemzeti Tankönyvkiadó, Budapest. 